\title{
30th International Conference on Flexible Automation and Intelligent Manufacturing (FAIM2021) special issue editorial
}

\author{
George-Christopher Vosniakos ${ }^{1} \cdot$ Marcello Pellicciari $^{2} \cdot$ Panorios Benardos $^{1} \cdot$ Angelos Markopoulos $^{1}$
}

Published online: 5 January 2021

(C) The Author(s), under exclusive licence to Springer-Verlag London Ltd. part of Springer Nature 2021

This special issue contains papers that were submitted to the 30th International Conference of Flexible Automation and Intelligent Manufacturing (FAIM) under a special 'FastTrack Review' call. The conference was originally scheduled to take place in Athens, Greece, in June 2020. However, due to the covid-19 pandemic it was decided to postpone it by one year, at the same time keeping the publications program unaltered. Thus, FAIM2020 has become FAIM2021 and the accepted papers appear in print before their actual presentation at the conference.

FAIM2021 marks 30 years of the conference series continuous presence in the international manufacturing scene addressing both technology and management issues. This particular edition emphasizes the inter-disciplinary nature of manufacturing by setting as main theme: 'Multiple, complementary and evolving facets of modern manufacturing: holistic synthesis'.

Indeed, manufacturing processes, machine tools/robotics and manufacturing systems are dealt with in the papers of this special issue. Individual viewpoints within these domains span product design, manufacturing process mechanics and material microstructure, tool design, monitoring, fault detection, process planning, manufacturing scheduling, factory design and manufacturing system configuration. Of the enabling technologies, machine learning seems to attract particular attention, followed by virtual reality, machine vision and various other IT tools.

Articles in the volume at hand are presented according to the following order logic: part design, process planning,

George-Christopher Vosniakos

vosniak@central.ntua.gr

1 School of Mechanical Engineering, National Technical University of Athens, Heroon Polytehniou 9, 15780 Athens, Greece

2 INTERMECH Interdepartmental Center, University of Modena and Reggio Emilia, Via Giovanni Amendola 2, 42122 Reggio

Emilia, Italy manufacturing process mechanics, machine tools, factory design, manufacturing planning and enabling technologies.

Enriching the publications outlet of FAIM by a major journal such as The International Journal of Advanced Manufacturing Technology (IJAMT) as an alternative to the normal proceedings and, indeed, allowing submissions to IJAMT beforehand rather than post-conference extended selected papers, turned out to significantly raise the conference's quality level as well as the interest in it as measured by the number of participants.

In this process, a large number of papers aspiring to be published in IJAMT had to be turned down. Nevertheless, their merit was high enough to justify their inclusion in the normal proceedings of the conference. The significantly heavier reviewing workload accompanying this idea and course of action was borne by FAIM2021 Scientific Committee, to which FAIM2021 Organizers are most grateful.

The Chairs of FAIM2021 would like to extend special thanks to Prof. Andrew Yeh-Ching Nee, IJAMT Editor-in-Chief, for his support of the conference and the 'Fast-Track Review' publication idea, as well as the excellent collaboration throughout the preparations stage. We would also like to acknowledge the staff of the editorial office of the Journal for their continuous care, efficiency and highly professional work.

We are looking forward to continuing this successful publications model in future FAIM conferences and we are extending an open invitation to the authors and audience of The International Journal of Advanced Manufacturing Technology to swell FAIM ranks.

30th FAIM Conference Chairmen: Professor GeorgeChristopher Vosniakos, General Chair; Professor Marcello Pellicciari, Industrial Relations Chair; Assistant Professor Panorios Benardos, Program Chair and Assistant Professor Angelos Markopoulos, Media Chair.

Publisher's note Springer Nature remains neutral with regard to jurisdictional claims in published maps and institutional affiliations. 